\title{
Measuring Success in Spine Care
}

\author{
Jens Chapman ${ }^{1}$ \\ ${ }^{1}$ Department of Orthopaedics and Sports Medicine, University of \\ Washington School of Medicine, Seattle, Washington, United States \\ Evid Based Spine Care J 2013;4:1.
}

Everything that can be counted does not necessarily count; everything that counts cannot necessarily be counted.

Albert Einstein

Spine surgery can be one of the most rewarding of medical specialties, yet spine care has invoked questions and even controversy from some circles. Undoubtedly, the well-being of humans is closely tied to a well-functioning spine, but maintaining it in well-functioning conditions through the course of a long and active lifetime is uncommon. Although it is well-known that a dysfunctional spine can cause its owner severe disability due to structural, neurologic, or painful circumstances, we frequently struggle to quantify these conditions and remain incomplete in providing irrefutable evidence of the effectiveness of some of our interventions. In our quest for validation of conditions and our interventions, we resort to metrics, frequently applied through tests. While these promise objectivity through reproducible quantification, the question remains: What do these tests actually measure and what do the results actually mean?

AOSpine recently published a comprehensive compilation of measurements used in spine care (a project in which I had the honor of serving as a coeditor). With this third book, Measurements in Spine Care, ${ }^{1}$ in a series titled Science in Spine Care, AOSpine set out to review all meaningful, clinical, spine-related tests, be they neurological, laboratory, radiographic, and more. The tests were then rated in a fashion similar to popular publications such as Consumer Reports and US News and World Report. As in our previous books, Spine Outcomes Measures and Instruments ${ }^{2}$ and Spine Classifications and Severity Measures, ${ }^{3}$ the editors were surprised with the paucity of meaningful and well-validated objective measurements in our discipline. Similar to our observations in the other areas of patient-related outcome measures and diseases/injury classification/severity ratings, our field is widely bereft of objective, reproducible quantifications of virtually all domains in which the well-being and function of spine are being tested. One of Albert Einstein's most famous insights yet again seems to be proven.

There are, however, many areas in which progress has been made, and functionality can be tested, such as in pulmonary function as an indirect expression of torso health
Address for correspondence Jens Chapman, MD, Department of Orthopaedics and Sports Medicine, University of Washington School of Medicine, 325 Ninth Avenue, Box 359798, Seattle, WA 98104, United States (e-mail: jenschap@u.washington.edu).

and simple walking or balancing tests for myelopathy. Many of these measurement opportunities are little known within the spine community due to a persistent "silo-mentality." Hopefully, this book will provide inspiration to the scientifically motivated members of the spine community to advance our endeavors with sound applications to measure success.

As for EBSJ, we have an easier time to measure success: readership numbers, being listed in large search engines, and impact factor. Aside from boasting one of the largest readerships in spine surgery with over 10,000 readers worldwide, we are now listed in PubMed and all the issues through early 2012 have been downloaded with a catching up to present day expected over the next few months. We have also made the strategic decision to begin merging some of our operations with Global Spine Journal published by Thieme. While maintaining our unique publication and in-depth review style, we will now be able to reach more colleagues and expand our popular systematic reviews to as many as four articles per issue by working with a respected large commercial publisher and offering expanded publication options to our scientifically minded spine practitioner readership. We hope that many of you will continue on the path of improving the quality of spine care and proving the value of what we are doing for our patients and society at large through steady application of sound, scientifically derived insights. Please do join us in this quest with your article submissions, reviews, and editorial board work with Global Spine Journal and Evidence-Based Spine-Care Journal as we meet the challenges of tomorrow's health care by learning from the failures of the past and present through sound scientific principles.

"Failure is success if we learn from it."
Malcolm Forbes

\section{References}

1 Chapman JR, Lee MJ, Hermsmeyer JT, Dettori JR, Norvell DC, eds. Measurements in Spine Care. New York, NY: Thieme; 2012

2 Chapman JR, Hanson BP, Dettori JR, Norvell DC, eds. Spine Outcomes Measures and Instruments. Stuttgart, Germany; New York, NY: Thieme; 2007

3 Chapman J, Dettori J, Norvell D, eds. Spine Classifications and Severity Measures. Stuttgart, Germany; New York, NY: Thieme; 2009 (c) 2013 Georg Thieme Verlag KG Stuttgart · New York
DOI http://dx.doi.org/ 10.1055/s-0033-1341595. ISSN 1663-7976. 